

\title{
Madrid y Burgos, 1936-1939: representación visual de las mujeres a través del fondo fotográfico de la guerra civil española de la biblioteca nacional
}

\author{
Madrid and Burgos, 1936-1939: visual representation of the women in the spanish \\ civil war through the national library's photograph archive
}

Beatriz de las Heras Herrero*

\begin{abstract}
Resumén: Basado en la necesidad de analizar la fotografía desde todos los prismas posibles, incluyendo su anverso y reverso, y en el argumento de que la fotografía es, ante todo, un acto icónico que requiere que se la interrogue, este artículo ha buscado discutir la representación visual de las mujeres a través del fondo fotográfico de la guerra civil española. Para lograr este objetivo, el artículo ha presentado algunos ejemplos visuales de las fotografías que retrataron la actividad de las mujeres que vivieron la guerra en Madrid y Burgos y El resultado de la investigación apunta a que, a pesar de que los mensajes lanzados tienen enunciación diferente, lo cierto es que las imágenes que se conservan muestran que la actividad de las mujeres de ambos lados fue la misma, aunque esas imágenes presentan características diferenciadas.
\end{abstract}

Palabras clave: Fotografía. Guerra Civil Española. Mujeres.

\begin{abstract}
Based on the need to analyze the photo from all prisms possible, including your front and back, and the argument that photography is primarily an iconic act that requiresthe questioning, this article has sought to discuss the representation visual of womenthrough the photographic collection of the Spanish Civil War. To achieve this objective, the paper has presented some visual examples of photographs that portray the activity of women who lived through the war in Madrid and Burgos and the result of researchsuggests that, Despite that the messages have different utterances, the fact is that the images are preserved show that the activity of women on both sides was the same, although these images have different characteristics.
\end{abstract}

Keywords: Photography. Spanish Civil War. Women.

\footnotetext{
* Doctora en Humanidades y Profesora de la Universidad Carlos III de Madrid en el Área de Historia Contemporánea del Departamento de Humanidades. Especialista en el estudio de la Guerra Civil Española desde las fuentes visuales: fotografía, cine y carteles. Ha sido profesora invitada en la Universidad de Burgos, Universidad Nacional de Lomas de Zamora (Argentina), Universidade de Sao Paulo (Brasil), Universidade Estadual do Sudoeste de Bahia (Brasil), Universidade Federal da Bahia (Brasil), en la Sorbonne Nouvelle, Paris III (Francia) y en el Middlebury Collage.
} 


\section{Las Mujeres de Madrid Y Burgos en la Biblioteca Nacional}

El Fondo Fotográfico de la Guerra Civil Española de la Biblioteca Nacional está compuesto por 44.000 fotografías clasificadas por asignación geográfica (tituladas y alfabetizadas por provincias) o temática, que se conservan en cajas y carpetas. A pesar de la intensa labor realizada por Pedro Ignacio Díaz Opacio e Isabel Ortega ${ }^{1}$, la colección ni está totalmente clasificada ni posee una estructura definitiva, debido, fundamentalmente, a la complejidad de trabajar con un fondo que se ha conformado, a través del tiempo, en distintas acciones recopilatorias llevadas a cabo durante y tras la guerra.

La colección se inicia con la creación de la Sección de la Guerra Civil Española del Ministerio de Información y Turismo creada en 1965 con el objetivo de conservar las fotografías de la Subsecretaría de Educación Popular (matriz de la colección) y de los archivos fotográficos que se encontraban en delegaciones o secciones de los distintos órganos del aparato estatal. En 1980, tras la disolución del Ministerio, la colección llega a la Biblioteca Nacional donde se integra con el resto del fondo fotográfico de la institución seis años después.

Esta peculiar conformación hace que el historiador se encuentre con una serie de escollos a la hora de laborar con el material fotográfico. A la dificultad de trabajar con un fondo disperso debemos sumar que estamos frente a un conjunto con un nivel identificativo incompleto que obliga al investigador a consultar de manera exhaustiva todas las carpetas y cajas. Por otro lado, un 30\% de las fotografías son copias que se realizaron hasta finales de los años 50 , complicando así el establecimiento de los criterios de originalidad.

En el Fondo existen cuatro cajas contenedoras de fotografías tomadas en la provincia de Madrid: Caja n ${ }^{\circ} .57$, Caja n $^{\circ} .60$, Caja n ${ }^{\circ} .61$ y

\footnotetext{
${ }^{1}$ KURTZ, Gerardo; ORTEGA, Isabel. 150 años de Fotografía en la Biblioteca Nacional: guía inventario de los fondos fotográficos de la Biblioteca Nacional. Madrid: Ediciones El Viso, 1989.
} 
Caja $n^{\circ} .109$. Estas componen un grueso de 1.562 instantáneas, a las que hay que sumar otras que están ordenadas en dos cajas sin inventariar: Caja $\mathrm{n}^{0} .58$ y Caja $\mathrm{n}^{\circ} .93$ bis. Al margen de la colección catalogada en estas cajas, localizamos otro conjunto de fotografías que rescata los restos visuales del Madrid de la Guerra, como las que se conservan en la Caja $n^{0} .40$ (asuntos varios sin identificar), o en las carpetas sueltas que están ordenadas por categorías temáticas. Por otro lado, dos cajas contienen imágenes de la ciudad de Burgos durante la contienda: la Caja n ${ }^{\circ} .74$ y la Caja $n^{\circ} .74$ bis, que conforman un corpus de 736 fotografías, a las que hay que añadir aquellas que se encuentran clasificadas en carpetas sueltas.

De entre el total, alguna de estas piezas rescata las huellas visuales de los distintos modelos de mujer que se fotografiaron en Madrid y Burgos durante la Guerra Civil Española. Existe en el fondo un total de 117 fotografías que retratan, de una manera directa, la actividad de la mujer de Madrid durante la contienda, ya sea en su faceta de madre y ama de casa, como en la de voluntaria en la vanguardia, pasando por su faceta como trabajadora de la industria de guerra, de política o sindicalista, o de miliciana en el frente. Fotografías que se distribuyen de la siguiente manera: 40 retratan a la mujer sublime, tres rescatan la imagen de la miliciana, 11 a la político-sindicalista y 67 corresponden a la imagen de la mujer de costumbres. (IGLESIAS RODRÍGUEZ, 1989). La mayoría de las instantáneas o no están selladas por ninguna casa de fotografía (exactamente 48) o están tomadas por fotógrafos que trabajaron en la ciudad entre julio de 1936 y marzo de 1939 (43 fotografías). El resto, 21 imágenes, están selladas por alguna institución oficial de Madrid que, según estos datos, mostraron menos interés en mantener para la eternidad, a través del clic de una cámara fotográfica, el papel desempeñado por las mujeres durante la Guerra Civil.

Respecto a las fotografías que recuperan la actividad de las mujeres en la ciudad de Burgos, podemos decir que existe un total de 346 imágenes. La mayoría de estas forman parte de los trabajos fotográficos que retrataron las actividades organizadas por la Sección Femenina, desde su sección de coros y danzas hasta la de avituallamiento y atención al herido. Menor 
es el número de imágenes que rescatan la actividad concreta de determinadas mujeres realizando las labores cotidianas. Dos fotografías inmortalizan a la mujer en el espacio que, según el ideario político del gobierno de Burgos, le correspondía por naturaleza: el del hogar; 11 imágenes recuperan su actividad en la calle, ya sea desempeñando su papel como abastecedora y madre, o como compañera en momentos de ocio; y nueve fotografías nos muestran su trabajo como voluntarias en la retaguardia (en locales comerciales, en talleres o realizando actividades asistenciales). Por otro lado, un número significativo de fotografías retratan la imagen a seguir por las mujeres que defendieron la liberación de España: Pilar Primo de Rivera, de la que se conservan retratos de estudio e imágenes de su labor en la retaguardia.

Una vez expuestos algunos rasgos de las fotografías que se conservan en el Fondo Fotográfico de la Guerra Civil Española de la Biblioteca Nacional, podemos hablar de dos diferencias significativas respecto a la producción fotográfica de las dos ciudades. Una localizada en el reverso y otra en el anverso de las imágenes: la firma de las fotografías y lo retratado por el fotógrafo.

La mayoría de las instantáneas tomadas por los profesionales que captaron la actividad de las mujeres de Burgos son trabajos anónimos sellados por la Sección Técnica del Ministerio del Interior, mientras que en el caso de las fotografías tomadas por los fotógrafos que retrataron ese tipo de escenas desde la vanguardia de Madrid no existe tanta homogeneidad. Una parte está sellada por los laboratorios fotográficos oficiales (Antifafot Madrid Laboratorio y Agencia Fotográfica del Partido Comunista o la Sección de Información Gráfica de la Delegación de Estado), aunque la mayoría corresponden a trabajos realizados por los fotógrafos de la ciudad o por aquellos que llegaron desde otros lugares para trabajar en Madrid. Podemos destacar las fotografías firmadas por Informaciones Gráficas P. Luís Torrents, Foto Vidal, Foto Walter, Baldomero Hijo, Foto Hermann, Foto Mayo, o Foto Redondo.

La segunda diferencia entre la producción fotográfica de una ciudad y otra se refiere a lo retratado, al anverso de la imagen. La fotografía es el 
mejor soporte para mostrar aquello que se quiere mostrar y las autoridades responsables de cada ciudad, siendo conscientes de este poder, la utilizaron como medio propagandístico. La mayoría de las instantáneas tomadas a las mujeres de Madrid centra su interés en la acción fotografiada, mientras que en el caso de las imágenes tomadas a las mujeres de Burgos el interés gira entorno a quién realiza la acción. Por otro lado, las fotografías que retratan a la madrileña la sitúa en un contexto con tintes más patéticos y desgarrados que las que retratan a la burgalesa, a la que parece no afectarle la situación que se vive en el país. El mensaje es claro en ambos lados de la contienda: en Madrid se muestran los horrores de una sublevación que ha llevado hambre, miseria y miedo, mientras que en Burgos se manifiesta la normalidad de la vida cotidiana.

Tras analizar de manera individual cada fotografía, teniendo en cuenta la información aportada tanto en su anverso como en su reverso, realizamos una selección de las imágenes más representativas, atendiendo al tipo de actividad desempeñada y a la imagen que se quería mostrar de la mujer que vivió la Guerra Civil Española en Madrid y en Burgos.

\section{Memoria Fotográfica de la Mujer: ¿Madrid versus Burgos?}

La Guerra Civil Española supuso una modificación en la tradicional distinción de los roles de género, puesto que la llamada a filas de los varones obligó a las mujeres a copar los puestos que ellos dejaron vacantes. Esta situación se vio de manera más evidente en las ciudades que apoyaron al gobierno constituido en el mes de febrero de 1936, donde la incorporación de las mujeres llegó hasta los puestos políticos y de representación sindical. Sin embargo, no podemos olvidar que en aquellas ciudades en las que se defendieron los valores de la España una, grande y libre, el papel de la mujer también se caracterizó por su actividad en el espacio de la retaguardia. Por tanto, aunque el mensaje dado a las mujeres 
desde las voces oficiales parecía mostrar dos modelos de mujer claramente diferenciados, lo cierto es que la imagen que de ellas podemos rescatar a través de esos fragmentos de memoria, que son las fotografías, nos indica que no existieron tantas desemejanzas.

A través de las imágenes que se conservan en el Fondo Fotográfico de la Guerra Civil Española de la Biblioteca Nacional, podemos observar una diferencia respecto a la visión que de las mujeres nos ofrecen esas huellas visuales: las fotografías tomadas en Madrid muestran tres prototipos diferentes de mujer en función de la actividad desempeñada y las tomadas en Burgos retratan un modelo único de mujer multifacética. Sin embargo, la contraposición de un prototipo de mujer en el caso de la burgalesa y de tres en el caso de la madrileña no debe inducirnos a error: mientras que las mujeres de Madrid responden al prototipo de mujer tradicional, mujer sublime o al de mujer activa en la defensa de la ciudad en el frente (la miliciana) o en la vanguardia (la político-sindicalista), las mujeres de Burgos responden al prototipo de mujer tradicional que también debe encargarse de alguna de las labores típicas de la mujer sublime, como la asistencia a enfermos o la ayuda en la industria de guerra, por lo que, salvo matices, representan el mismo prototipo. Por otro lado, y aunque al principio de la contienda las mujeres tomaron un papel activo en la defensa de Madrid desde la vanguardia (alejándose del modelo de mujer sumisa que debía esperar al hombre lejos del frente, es decir, del modelo de las ciudades defensoras de la sublevación militar del mes de julio de 1936), pronto se entendió que su actividad era más productiva en la segunda fila, popularizándose el lema “Hombres al frente, mujeres a la retaguardia”. Incluso desde los órganos anarquistas que habían animado a las mujeres a acudir al frente y habían luchado por la igualdad de sexos, se modificó el discurso para adaptarlo a la nueva situación:

[...] No vaciló, y decidida se lanzó a la calle a luchar al lado del obrero, compañero o no. Y ofreció su vida joven, pletórica de ilusiones juveniles en las primeras jornadas de la lucha heroica en que cada hombre era un héroe y cada mujer equivalía a un hombre. Pero no todo consiste en el valor, en esta lucha larga y continua 
de dos clases que se odian a muerte. La mujer, comprendiéndolo así, recapacitó y comprendió que las escaramuzas callejeras distan mucho de parecerse a la lucha metódica, regular y desesperante, de la guerra de trincheras. Comprendiéndolo así y reconociendo su propio valor, como mujer, prefirió cambiar el fusil por la máquina industrial y la energía guerrera por la dulzura de su alma de mujer. ${ }^{2}$

Este mensaje no parece alejarse del lanzado desde la españa azul para animar a las mujeres a participar activamente en la defensa de la cruzada española de 1936:

Y la prestación femenina, que en parte era ya un hecho, es
actualmente necesaria en multitud de organizaciones y servicios
que funcionan en la retaguardia. Son los Hospitales, los talleres y
roperos donde se confeccionan y clasifican multitud de prendas
y donde se llevan a efecto la “Campaña contra el frío”. Es el “Auxilio
Social” con sus múltiples facetas, es en definitiva, la asistencia,
cariño y afecto de vuestra juventud a los combatientes y a los
heridos de guerra.
¡Madre!. ¡Hermana!. ¡Novia!. ¡Madrinas de guerra!: Hoy empezáis
a construir los hogares de mañana; cuando vuelvan los vuestros
con los lauros de la victoria, prepararles el jersey y de vuestro
amor y el abrigo de una familia española y cristiana. ¡Viva España!.

Por tanto, nuestro punto de partida es el siguiente: las actividades que realizaron las mujeres en la retaguardia madrileña y burgalesa fueron las mismas y tan sólo se diferenciaron en algunos matices, que también se observan tras analizar las fotografías que se conservan en el Fondo Fotográfico de la Guerra Civil Española de la Biblioteca Nacional. Estos documentos gráficos nos muestran una imagen similar de las mujeres que vivieron en Madrid y Burgos el desarrollo de la contienda, pero con pequeñas diferencias que fueron explotadas por las autoridades políticas correspondientes, que entendieron las ventajas de emplear un soporte que, por su cercanía con la realidad, se entendía como elemental para

\footnotetext{
${ }^{2}$ Las mujeres en los primeros días de lucha. Mujeres Libres, v. 10, p. 3, 1937.

${ }^{3}$ España: la mujer y la prestación personal. Jaca, v. 26, p. 3, 1937.
} 
controlar el mensaje que se quería lanzar a los afines, a los enemigos y a los neutrales:

Se ha escrito mucho, resaltando la gran importancia que para nosotros y para nuestra causa tiene el desarrollo de una propaganda sistemática y organizada en las filas enemigas. No nos costaría mucho trabajo señalar infinidad de casos que demuestran esa realidad. Allí donde la propaganda se lleva a cabo con constancia y organización, los frutos no se hacen esperar: decenas de evadidos del campo faccioso vienen a nuestras filas; decenas de nuevos combatientes que gana nuestro Ejército, un debilitamiento y una desmoralización constante del enemigo. ${ }^{4}$

De hecho, y a pesar de los esfuerzos empleados por las autoridades de ambas ciudades para controlar la imagen que de estas se tomaba, lo cierto es que podemos apreciar maneras diferentes de mirar la realidad a través del objetivo de una cámara fotográfica. Este hecho se hace más patente en las fotografías que se realizaron en Madrid durante la contienda y que se conservan en la Biblioteca Nacional. Pongamos un ejemplo visual:

Figura 1

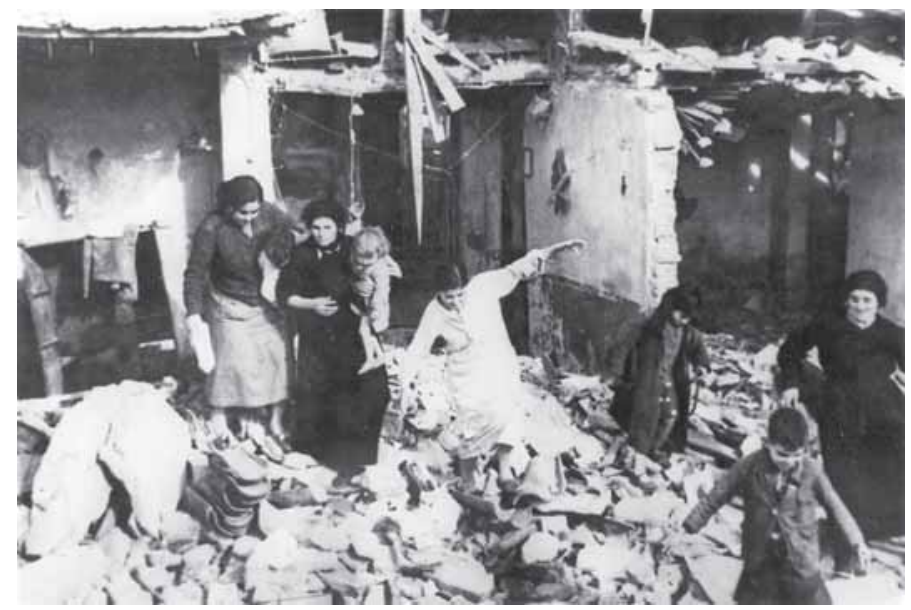

Fuente: Biblioteca Nacional: Fondo Fotográfico de la Guerra Civil Española. Carpeta 78, Sobre 3

\footnotetext{
${ }^{4}$ Nuestra propaganda en las filas facciosas. La Voz del combatiente, v. 23, p. 5, 1937.
} 
Figura 2

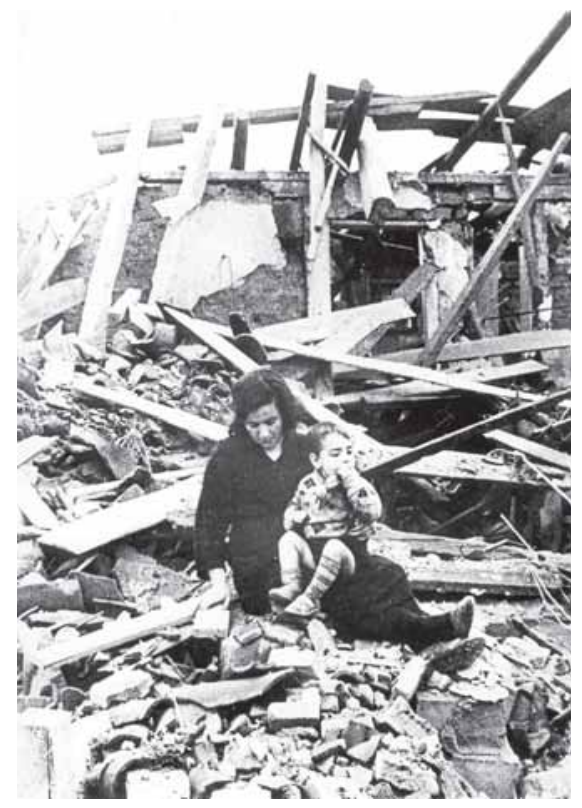

Fuente: Biblioteca Nacional: Fondo Fotográfico de la Guerra Civil Española. Carpeta 81

Ante un mismo hecho, la visita de mujeres a sus hogares tras un bombardeo en la ciudad de Madrid, el enfoque es diferente. Mientras que la figura 2 (sellada por el Servicio de Propaganda del Servicio Fotográfico del Ministerio de Exteriores) refleja una mujer abatida sobre los restos de una casa en Tetuán de las Victorias, la figura 1 (sellada por las casa barcelonesa P. Luis Torrents) muestra una actitud diferente ante la acción: las mujeres no se sientan a contemplar el resultado del bombardeo, sino que intentan recuperar aquellos enseres que les puedan resultar útiles en sus nuevas residencias. La totalidad de fotografías que retratan a la mujer de costumbres madrileña y que están selladas por los fotógrafos oficiales (entendiendo por oficial aquel que trabaja para una institución pública) responde al prototipo de mujer pasiva, víctima de lo que ocurre, mientras que las fotografías tomadas por los fotógrafos oficiosos (los que trabajaron para las distintas casas de fotografía de Madrid y de otras localidades) muestran la imagen de una mujer combativa que lucha contra 
la sublevación desde la retaguardia. El motivo parece estar claro: la imagen de la mujer de costumbres abatida que se muestra en carteles, documentales y fotografías tomadas por las autoridades antifascistas resulta más exportable para denunciar al mundo las siniestras consecuencias de una sublevación militar, que la imagen de una mujer que intenta acomodarse a las exigencias impuestas por el estallido del conflicto.

Una vez anunciada nuestra hipótesis de que, salvo matices y a pesar de los mensajes lanzados desde los órganos oficiales, la actividad de las mujeres de Madrid y Burgos fue la misma, y tras advertir que la fotografía fue empleada por las autoridades para mostrar aquello que se quería mostrar, pasaremos a analizar una serie de ejemplos visuales en tres espacios de trabajo de la retaguardia: el trabajo en talleres y fábricas, el trabajo voluntario y de asistencia, y el trabajo de ama de casa.

\section{Trabajo en talleres, fábricas y comercios}

Como ya hemos comentado, la retaguardia de las ciudades españolas se vio directamente afectada por la situación vivida en la vanguardia. Entre otros muchos cambios, la llamada a filas del hombre hizo que las mujeres de las dos españas tuvieran que copar puestos en los talleres, fábricas y comercios.

En el Fondo Fotográfico de la Guerra Civil Española de la Biblioteca Nacional, existe un total de 40 fotografías que retratan a las mujeres de Madrid trabajando en locales comerciales y fábricas, mientras que son nueve las imágenes conservadas que captan esta actividad en la ciudad de Burgos. Sin embargo, encontramos algunas diferencias que se aprecian en los siguientes ejemplos visuales: mientras que en la figura 3 (tomada en Burgos, sin data, y en cuyo reverso puede observarse un sello del Ministerio del Interior) se presenta una imagen, podríamos decir, ordenada en la que se retrata a un grupo de mujeres trabajando en una fábrica de sedas y en la que por el ángulo de la toma se muestra una actividad en grupo sin destacar individualidades, en la figura 4, tomada en Madrid, se muestra una imagen en la que hombres y mujeres trabajan por 
igual en una fábrica de montaje de aeroplanos, un espacio que no se presenta tan ordenado y en el que se crea un marco de laboro común sin que el género de cada trabajador influya en el resultado final: su aportación a la defensa de Madrid.

Figura 3

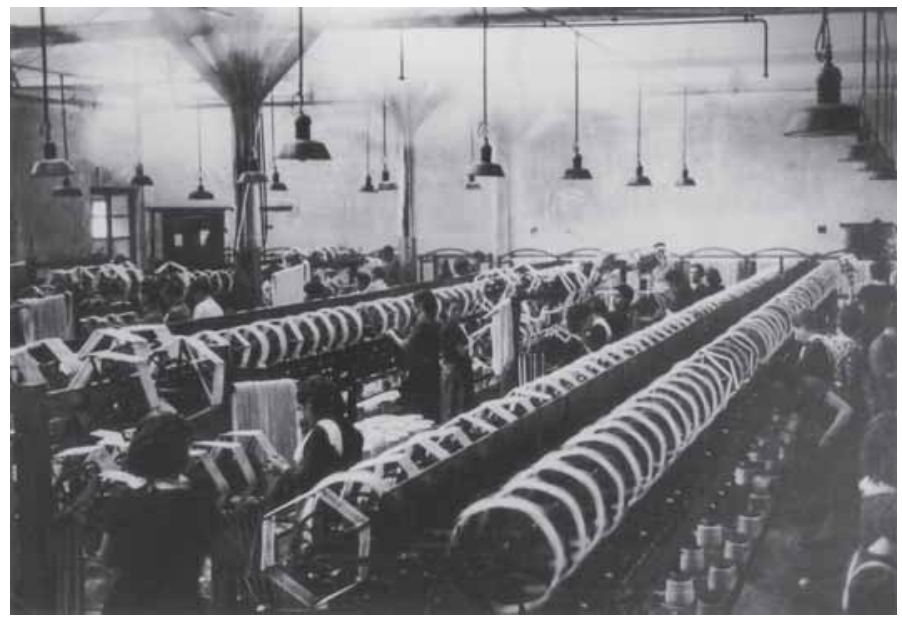

Fuente: Biblioteca Nacional: Fondo Fotográfico de la Guerra Civil Española.

Caja 74, Sobre 4

Figura 4

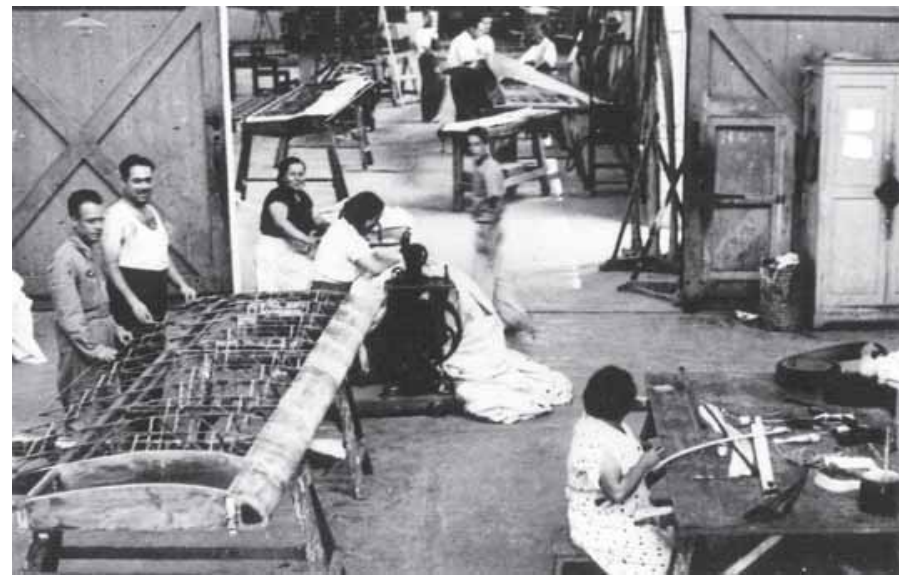

Fuente: Biblioteca Nacional: Fondo Fotográfico de la Guerra Civil Española.

Caja 93 bis, Sobre 12 
Figura 5

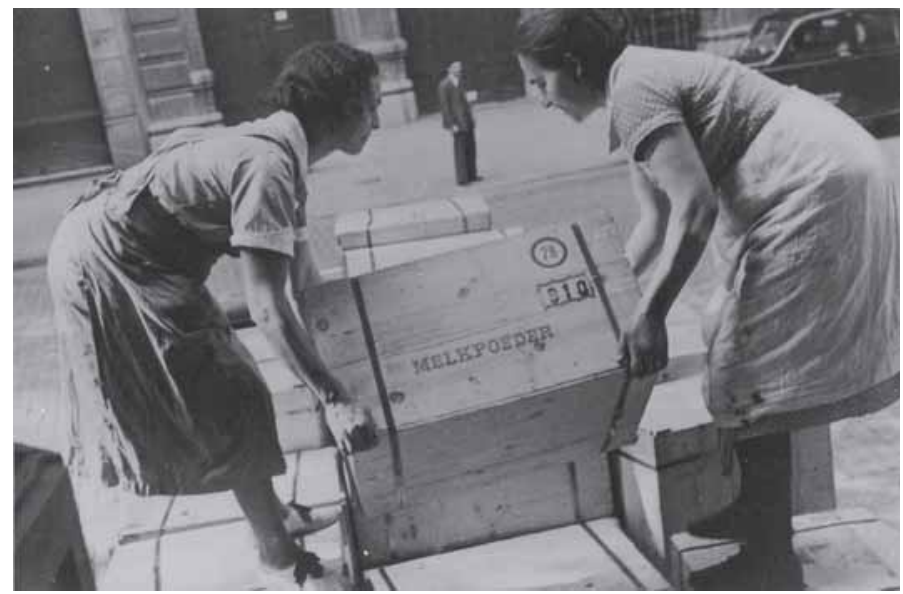

Fuente: Biblioteca Nacional: Fondo Fotográfico de la Guerra Civil Española. Carpeta 49, Sobre 2

Figura 6

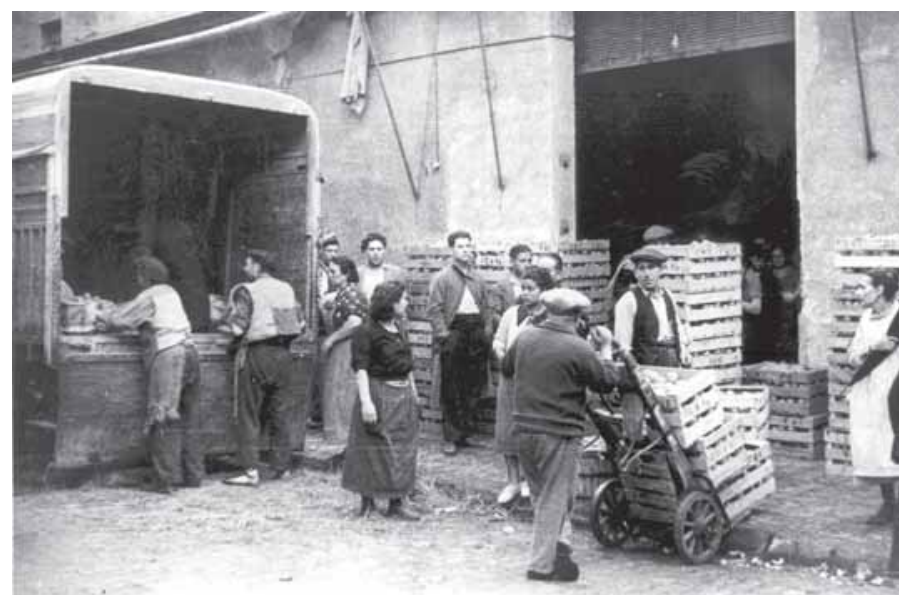

Fuente: Biblioteca Nacional: Fondo Fotográfico de la Guerra Civil Española. Caja 58, Sobre 11

La misma imagen se muestra en los siguientes documentos gráficos. En la figura 5 (sellada en su reverso por el Ministerio del Interior) se retrata a dos mujeres pertenecientes a Auxilio Femenino cargando una caja en la ciudad de Burgos. De nuevo, el espacio de trabajo de la 
mujer se muestra como exclusivamente femenino, sin que aparezca una figura masculina, que sí se hace visible en las fotografías que retratan la actividad en la retaguardia madrileña, como se muestra en la figura 6 (un trabajo del fotógrafo P. Luis Torrents y en cuyo reverso puede leerse “Suministro para los frentes”). En esta imagen se retrata una actividad en la que trabajadores, sin distinción de género, comparten espacio y responsabilidades.

Pongamos un nuevo ejemplo visual, el que rescata la imagen de mujeres pesando y empaquetando las bolsas de racionamiento que se repartían en los locales comerciales de la retaguardia burgalesa y madrileña. Mientras que en la figura 7 (una imagen tomada en la ciudad de Burgos en la que se retrata a dos mujeres manipulando alimentos) lo más importante es mostrar la actividad laboral en sí, en la figura 8 (un trabajo anónimo) lo fundamental es demostrar esa convivencia laboral pacífica entre hombres y mujeres, incluso perjudicando la propia calidad de la toma fotográfica por la abertura del plano necesaria para retratar al hombre que aparece al fondo.

Figura 7

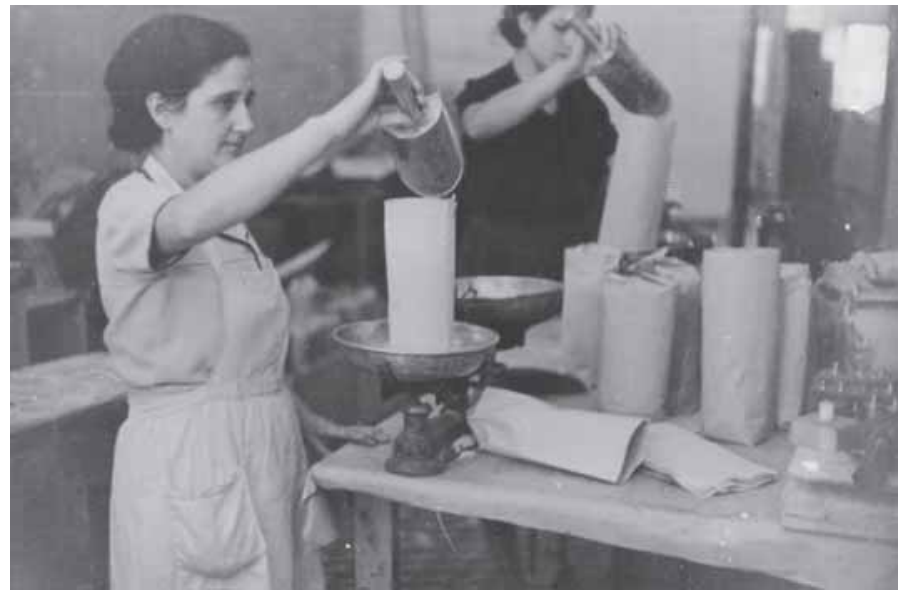

Fuente: Biblioteca Nacional: Fondo Fotográfico de la Guerra Civil Española.

Carpeta 449, Sobre 2 
Figura 8

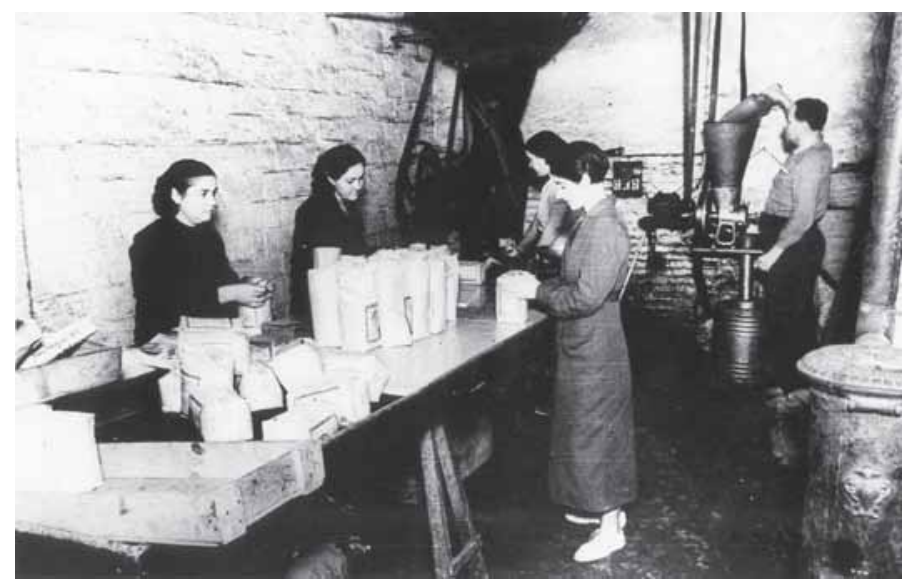

Fuente: Biblioteca Nacional: Fondo Fotográfico de la Guerra Civil Española. Carpeta 208, Sobre 11

Este interés por confirmar visualmente un marco de estrecha colaboración entre hombres y mujeres podría deberse a la preocupación que mostraron las autoridades responsables de Madrid por acabar con especulaciones que apuntaban a que la incorporación de la mujer a los espacios laborales que habitualmente estaban reservados al hombre, podría perjudicarle tras finalizar la guerra. Tal fue el clima de tensión que se creó por este tema que incluso la prensa de la época tuvo que desmentir esta aseveración desde algunos artículos y editoriales, como en el diario El Sol, en el que se publicó “La mujer en la fábrica no desplaza al hombre”. Esta problemática también fue recogida en un discurso que Dolores Ibarruri, La Pasionaria, ofreció en el año 1938, en el que se escuchó:

Tenemos que vencer el egoísmo y la cobardía de algunos hombres, aunque ellos se llamen de izquierdas. Algunos de los que blasonan de ser hombres avanzados y progresivos, cuando se les habla de que su mujer debe pertenecer a una organización o a un partido, o de que su mujer debe tomar parte activa en la lucha, contestan siempre con la misma cantinela: "Mi mujer no sabe; mi mujer no entiende; mi mujer tiene muchos hijos”. Sin embargo, aquella mujer que piensa que no sabe, que no entiende, que no comprende, entiende, sabe y comprende mejor que él. 
En grado mínimo ha sido incorporada la mujer a la producción, y para vosotras es un orgullo saber que ayer mujeres que no conocían el uso del torno, que anteayer mujeres que no conocían el funcionamiento de la fresadora, trabajan con fe y entusiasmo y, a veces, superan en rendimiento a hombres que llevan muchos años en este trabajo.

Es un gran problema; y lo más doloroso es que tenemos que luchar con la incomprensión de nuestros propios compañeros. (IBARRURI, 1938, p.7-8).

Por tanto, el fotografiar constantemente al hombre y a la mujer trabajando unidos por la defensa de Madrid, al margen de mostrar una realidad, podría tener una intencionalidad velada: demostrar que hombres y mujeres podían compartir un mismo espacio de trabajo de manera solidaria y acabar así con rumores infundados.

La conclusión es la siguiente. Parece como si las fotografías tomadas en la ciudad burgalesa quisieran reflejar, más que la actividad en sí, quien desempeña esa labor, de ahí que la toma se centre más en el retrato de la mujer como colaboradora en la retaguardia que en el espacio o la acción, mientras que las fotografías tomadas en Madrid parecen insistir en retratar el espacio en el que se desarrolla la actividad laboral, un espacio que, finalmente, se muestra como ámbito de cooperación entre hombres y mujeres. Esto explicaría por qué las fotografías tomadas en Madrid retratan un horizonte más dilatado, una vista más general, que las fotografías tomadas en Burgos, en las que, en su mayoría, se muestra al sujeto fotografiado, sin importar lo que le rodea.

\section{Labores asistenciales}

En el Fondo Fotográfico de la Guerra Civil Española de la Biblioteca Nacional, existe un total de 26 fotografías que retratan la actividad asistencial de las mujeres en Burgos y 23 instantáneas que lo hacen en Madrid, ya sea atendiendo médicamente a civiles y militares, 
recogiendo donativos con objetivo solidario, tejiendo y cosiendo ropa para el frente, cuidando a niños y enfermos, etcétera. Sin embargo, y a pesar de que se retratan las mismas escenas en los dos espacios estudiados, podemos apreciar algunas diferencias. Para ello emplearemos, de nuevo, ejemplos visuales.

En la figura 9 se observa una estampa coral formada por un grupo de 13 mujeres de Auxilio Femenino, de distintas edades y que se encuentran empaquetando algunas prendas (curiosamente todas menos la tercera de la izquierda mantienen la mirada artificialmente hacia la mesa en la que el grupo labora). Mientras, en la figura 10 (una imagen sellada por la Sección Prensa Extranjera del Ministerio de Estado) se retrata el trabajo de unas mujeres que se encargan de coser y bordar ropas en Madrid con el mismo objetivo: el envío al frente. En esta imagen lo importante es fotografiar la colaboración de las mujeres en una actividad, por lo que la imagen está tomada desde el fondo de la habitación, mostrando la labor de equipo. Sin embargo, en la fotografía anterior, claramente posada, lo importante no es mostrar la acción, de nuevo, lo importante es mostrar quién la realiza.

Esta situación aparece contraria en el siguiente ejemplo visual.

Figura 9

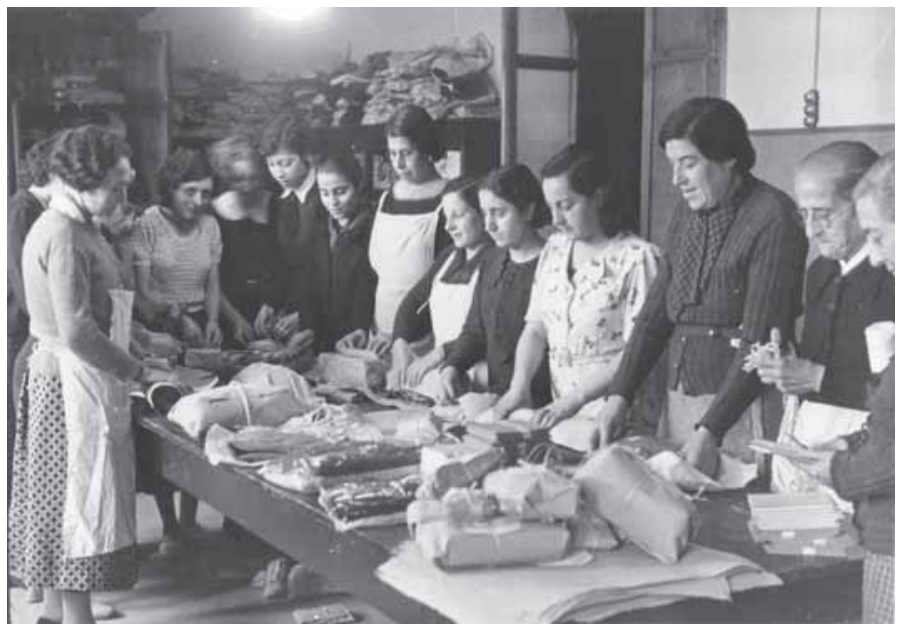

Fuente: Biblioteca Nacional: Fondo Fotográfico de la Guerra Civil Española.

Carpeta 449, Sobre 7 
Figura 10

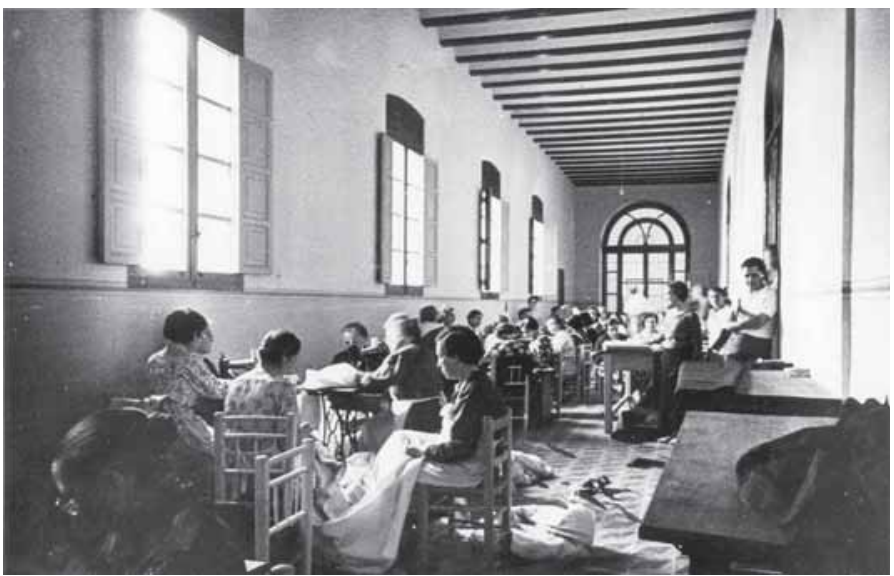

Fuente: Biblioteca Nacional: Fondo Fotográfico de la Guerra Civil Española. Carpeta 242

Mientras que en la figura 11 (un trabajo sellado por el Ministerio del Interior y en cuyo reverso puede leerse: "Fiesta organizada por el Cuadro Artístico de Frentes y Hospitales. Llegada de heridos para presenciar la fiesta y son ayudados por la enfermeras con las cuales conversan”) se retrata a una enfermera charlando de manera distendida con dos soldados en el patio del hospital musulmán de Burgos, en la figura 12 (trabajo realizado por Foto Redondo, y en cuyo reverso puede leerse "Trabajo voluntario. Curando una pequeña herida”) lo importante es resaltar que esa labor está realizada por una mujer y que a quien atiende es a otra mujer que viste el mono de miliciana, de ahí que la imagen se tome desde un plano bajo que resalta la figura de las protagonistas.

En este caso, lo importante sí es destacar que los sujetos fotografiados son mujeres, en concreto que una de ellas (la que viste la indumentaria típica de las calles de Madrid desde julio de 1936, el mono de trabajo) es una mujer y que desarrolla alguna actividad de defensa de la ciudad, ya sea desde la vanguardia o la retaguardia. La intención del fotógrafo, por tanto, es clara: el elemento a retratar es el personaje, no la actividad desempeñada por él, personaje, el de la miliciana, que desde el primer día de guerra interesó por lo novedoso de su aportación en la 
defensa de la ciudad y que se empleó en distintos soportes visuales (el cartelístico, el fotográfico y el cinematográfico) como elemento propagandístico por parte de las autoridades de la ciudad.

Por tanto, llegamos a la siguiente conclusión: de nuevo, las fotografías que retratan la actividad de la mujer en su dedicación a distintas labores asistenciales tomadas en Burgos se centran en mostrar quién realiza la acción, mientras que las que retratan algún espacio de Madrid lo hacen en la propia acción asistencial, excepto en el caso de aquellas imágenes que, intencionadamente propagandísticas, retratan la labor de algunas milicianas.

Figura 11

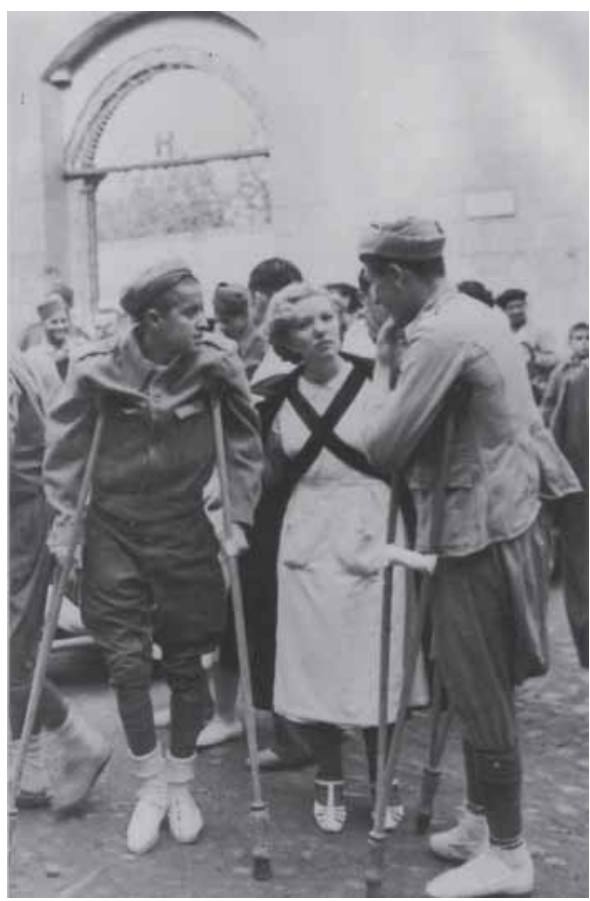

Fuente: Biblioteca Nacional: Fondo Fotográfico de la Guerra Civil Española. Caja 74 bis, Sobre 14 
Figura 12

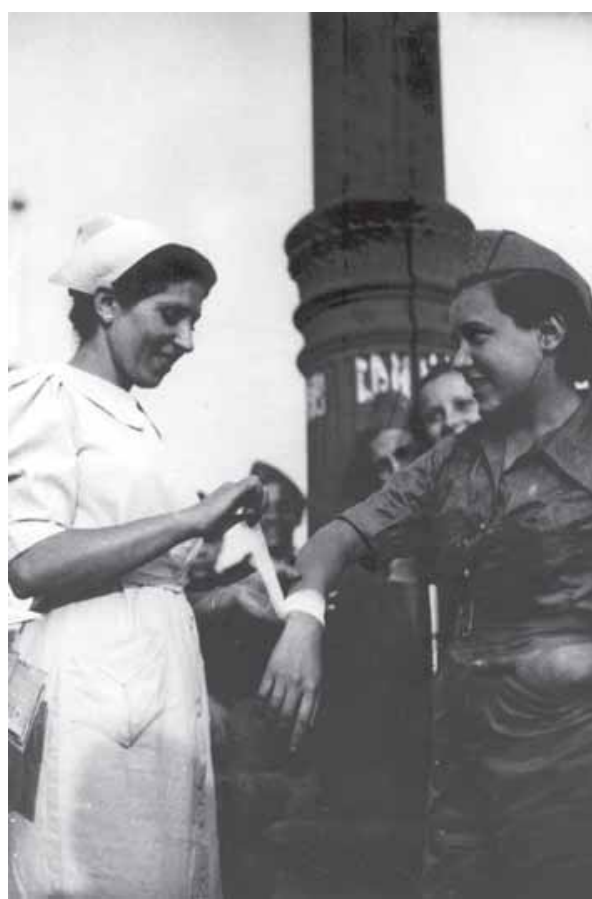

Fuente: Biblioteca Nacional: Fondo Fotográfico de la Guerra Civil Española.

Caja 93 bis, Sobre 12

\section{El trabajo de ama de casa}

Existe otro conjunto de imágenes que, mostrando una misma actividad realizada por la mujer, connotan circunstancias diferentes: las que reflejan el trabajo como ama de casa. Concretamente, en el Fondo Fotográfico de la Guerra Civil Española de la Biblioteca Nacional se conservan 13 imágenes que retratan la actividad de las burgalesas como amas de casa y 67 fotografías que lo hacen de las madrileñas.

Mientras que en Burgos el trabajo de las mujeres llevando a cabo las tareas propias del hogar está caracterizado por la normalidad 
de la vida cotidiana, esta actividad se muestra de manera diferente en las fotografías tomadas en Madrid, de tal manera que estas están cargadas de un patetismo que se contrapone a la normalidad que desprenden aquellas.

Pongamos dos ejemplos. Mientras que en la figura 13 (un trabajo sellado por el Ministerio del Interior y en cuyo reverso se lee "Normalidad completa en Burgos así como en las demás poblaciones de la España Liberada”) se retrata a unos niños, bien vestidos y alimentados, que juegan saludablemente en el Parque del Espolón al cuidado de sus ayas o madres, la figura 14 retrata a unos niños que sucios y harapientos se encuentran en mitad de una calle de Madrid junto a sus madres famélicas, desarregladas y que pasan la mayor parte del tiempo en la calle para tener en el punto de mira el cielo y así poder divisar los aviones enemigos antes de que inicien el bombardeo sobre la ciudad.

Figura 13

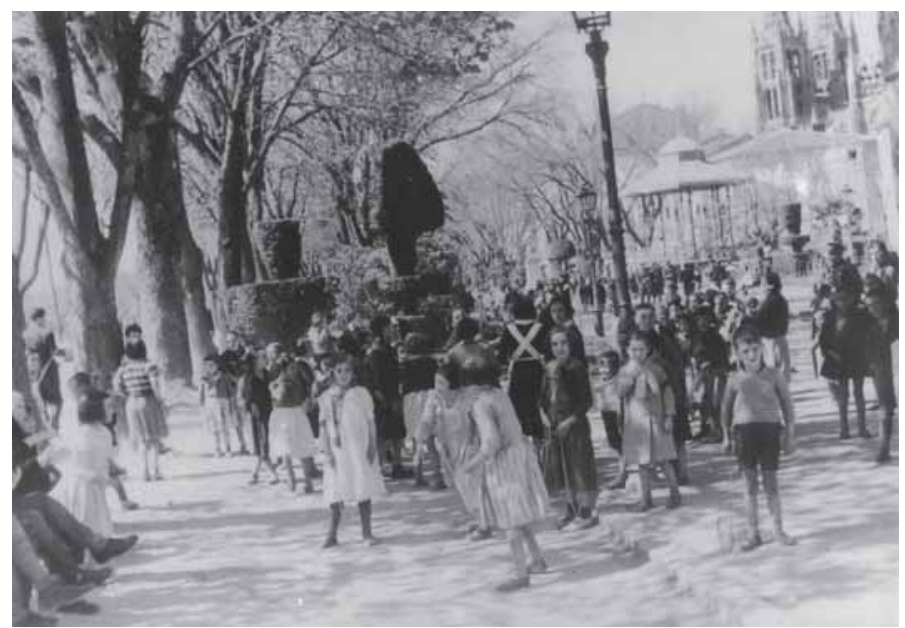

Fuente: Biblioteca Nacional: Fondo Fotográfico de la Guerra Civil Española. Caja 74, Sobre 4 
Figura 14

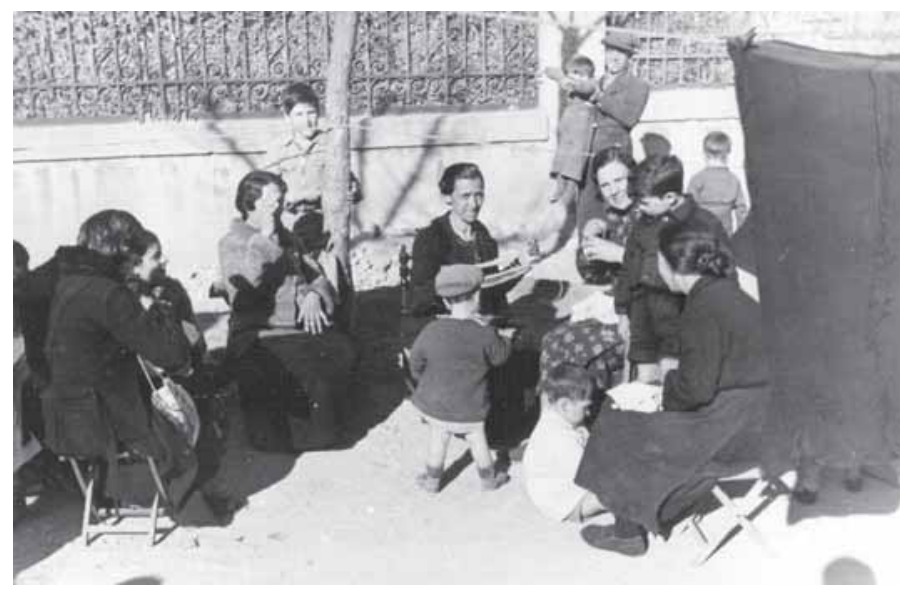

Fuente: Biblioteca Nacional: Fondo Fotográfico de la Guerra Civil Española. Caja 57, Sobre 19

Lo mismo ocurre en las siguientes imágenes tomadas en un espacio de la retaguardia transitado por las mujeres diariamente durante la contienda: los mercados. Mientras que en la figura 15 (un trabajo sellado por el Ministerio del Interior y en cuyo reverso puede leerse "Puestos del mercado en el que puede verse la abundancia de fruta, etc.”) se retratan puestos callejeros que no han sufrido las secuelas propias de una situación bélica, en la figura 16 se ve a un grupo de mujeres que hacen una de las famosas colas ante el esqueleto, aún humeante, del Mercado de El Carmen. De nuevo se muestran las consecuencias de la guerra y, de nuevo, se presenta una imagen patética de la vida cotidiana de las mujeres de Madrid.

Es decir: frente a la normalidad reflejada a través de las fotografías tomadas en Burgos (ciudad en la que parece como si la guerra no hubiera interrumpido el ritmo de la vida cotidiana), la anormalidad de la vida diaria que se retrata en Madrid, ciudad en la que no se vive, se sobrevive. 
Figura 15

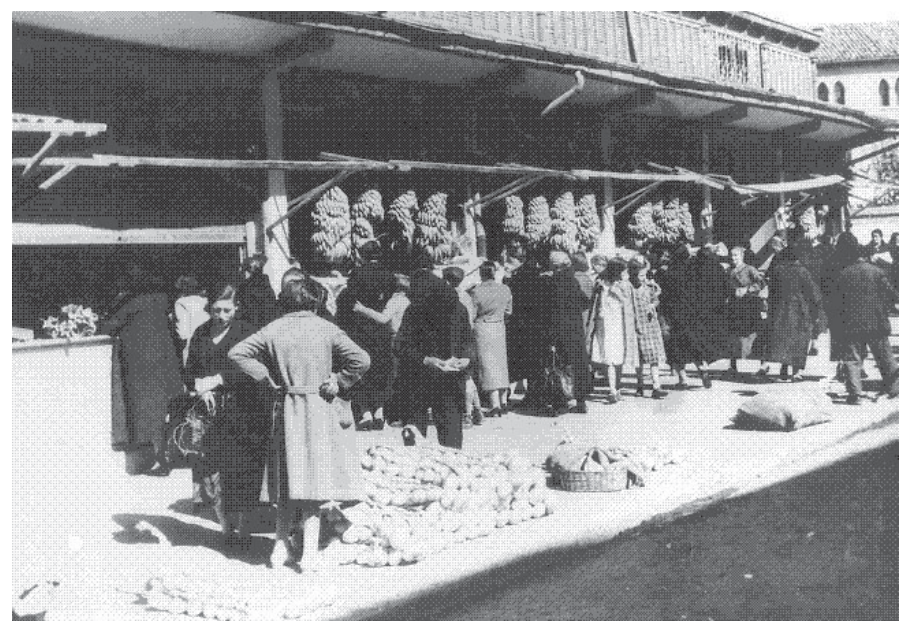

Fonte: Biblioteca Nacional: Fondo Fotográfico de la Guerra Civil Española. Caja 74, Sobre 4

Figura 16

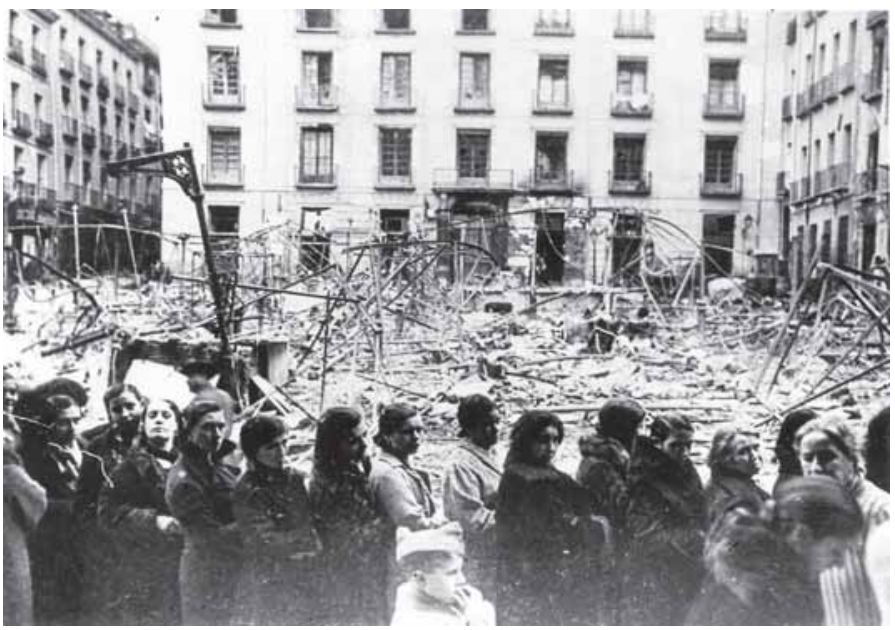

Fonte: Biblioteca Nacional: Fondo Fotográfico de la Guerra Civil Española. Carpeta 79 


\section{Conclusiones}

La fotografía corta el espacio y captura el tiempo de aquello que retrata, por lo que resulta un soporte de memoria fundamental para desarrollar discursos explicativos históricos, más en nuestro caso, ya que trabajamos en un período de la historia durante el cual España se convirtió en un país pionero en lo concerniente al dominio de la propaganda en distintos soportes, entre ellos el visual. Este es el motivo por el que para realizar un buen análisis de las fotografías, y para poder destapar alguna información que podría estar velada en un primer vistazo, se debe partir de la base de que la fotografía es, ante todo, un acto icónico que requiere que se la interrogue (DUBOIS, 1986, p.21), y una huella de un real, no un espejo de lo real. Por tanto, la fotografía es objeto a analizar desde todos los prismas posibles, incluyendo el de su anverso (lo que se retrata) y reverso (la autoría y descripciones complementarias), además del de las propias características del fondo que la conserva.

Teniendo en cuenta este punto de partida, hemos presentado, a modo de apunte, algunos ejemplos visuales de las fotografías que retrataron la actividad de las mujeres que vivieron la guerra en Madrid y Burgos, y que se conservan en el Fondo Fotográfico de la Guerra Civil Española de la Biblioteca Nacional.

El resultado de la investigación apunta a que, a pesar de que los mensajes lanzados desde los órganos políticos de los alzados y desde los político-sindicales de los defensores de la República eran distintos, lo cierto es que las imágenes que se conservan muestran que la actividad de las mujeres de ambos lados fue la misma, aunque esas imágenes presentan características diferenciadas. En las fotografías tomadas a las mujeres de Burgos se retrata un modelo único de mujer multifacético, prima la idea de conjunto sobre la del individuo, el interés fotográfico reside en quién realiza la acción (una actividad que se revela como específicamente femenina), se muestra una imagen más ordenada (la guerra no ha alterado la forma de vivir o estar en la retaguardia) y en su mayoría son fotografías selladas por la Sección Técnica del Ministerio del Interior. Mientras, las fotografías tomadas a las mujeres de Madrid retratan distintos modelos de mujer que 
desempeñan labores concretas (la mujer de costumbres, la mujer sublime y la mujer antifascista), tienen un carácter más individual, el interés fotográfico se centra en la acción fotografiada (en muchos casos, una actividad en colaboración con el hombre con un único objetivo: la defensa de la ciudad), se muestra una imagen más desordenada de la vida en la retaguardia (connotando, de esta manera, las graves consecuencias de la sublevación sobre la población civil), y la autoría no resulta tan homogénea marcando una clara distinción entre las fotografías que son tomadas para una institución oficial de carácter político-sindical (como el Ministerio del Interior, la Delegación de Estado o el Partido Comunista) o las fotografías de los fotógrafos oficiosos, como P. Luis Torrents, Foto Vidal, Foto Walter o Foto Mayo, entre otros.

\section{Referencias}

ABELLA, Rafael. La vida cotidiana durante la guerra civil: la España republicana. Barcelona: Planeta Historia y Sociedad, 2004.

BRISSET, Demetrio. Fotos y cultura: usos expresivos de las imágenes fotográficas. Málaga, 1985. Textos Mínimos.

BURKE, Peter. Visto y no visto: el uso de la imagen como documento histórico. Barcelona, Crítica, 2001.

DÍAZ BARRADO, Mario Pedro. Imagen y tiempo presente: información versus memoria. In: . (Coord.). Historia del tiempo presente: teoría y metodología. Salamanca: Universidad de Extremadura, 1998.

DUBOIS, Philippe. El acto fotográfico: de la representación a la recepción. Barcelona: Paidós Comunicación, 1986.

FRASER, Ronald. Recuérdalo tú y recuérdalo a otros: historia oral de la Guerra Civil Española. Barcelona: Crítica, 2001. 
FREUND, Giselle. La fotografía como documento social. Barcelona: Fotografía, 1993.

GUBERN, Roman. Del bisonte a la realidad virtual: la escena y el laberinto. Barcelona: Anagrama, 1996.

IBARRURI, Dolores. ¡A las mujeres madrileñas!. Madrid: Partido Comunista de España, 1938.

IGLESIAS RODRÍGUEZ, Gema. Derechos y deberes de las mujeres durante la Guerra Civil española: los hombres al frente, las mujeres en la retaguardia. In: JORNADAS DE ESTUDIOS MONOGRÁFICOS: Las mujeres y la guerra civil española., 3., 1989, Salamanca. Anales... Salamanca: Ministerio de Asuntos Sociales, 1989.

KURTZ, Gerardo; ORTEGA, Isabel. 150 años de Fotografía en la Biblioteca Nacional: guía inventario de los fondos fotográficos de la Biblioteca Nacional. Madrid: Ediciones El Viso, 1989.

MOLES, Abraham. La imagen. México: Trillas, 1991.

NASH, Mary. La miliciana: otra opción de combatividad femenina antifascista. In: JORNADAS DE ESTUDIOS MONOGRÁFICO, 3., 1989, Salamanca. Las Mujeres y la Guerra Civil Española. Salamanca: Ministerio de Asuntos Sociales, 1991. p.97-108.

PANTOJA, Antonio. Memoria en soporte digital. La transición a la democracia en España. Director: Mario P. Díaz Barrado. Universidad de Extremadura. Departamento de Historia, 2005.

RODRIGUEZ DE LAS HERAS, Antonio. Imagen histórica y edición electrónica. Ayer, Madrid, v.24, p.173-1783, 1996.

SÁNCHEZ VIGIL, Juan Miguel. El universo de la Fotografía: prensa, edición y documentación. Madrid: Espasa, 1999. 